\title{
An analysis of the interaction between industrial structure protection, ecological resources and environmental pollution externalities based on PSR model
}

dechun Wang ( $\nabla$ dechunwang1989@163.com )

Chongqing University https://orcid.org/0000-0001-9269-836X

\section{Research Article}

Keywords: landscape ecological security, PSR model, geomorphic disaster, middle and lower reaches of the Yangtze River Basin

Posted Date: August 27th, 2021

DOI: https://doi.org/10.21203/rs.3.rs-680929/v1

License: (9) This work is licensed under a Creative Commons Attribution 4.0 International License. Read Full License 


\section{Abstract}

Taking the middle and lower reaches of the Yangtze River Basin in Hubei Province as the research area, based on the "pressure state response" framework model, the evaluation index system of landscape ecological security in the basin is constructed, and its spatiotemporal change process and characteristics are discussed. The results show that the comprehensive index of landscape ecological security in the middle and lower reaches of the Yangtze River is gradually rising, and the area above the middle and high security level accounts for $52 \%$ of the total area of the study area. The high safety areas in the basin are mainly concentrated in the areas with good vegetation coverage, such as natural reserves and forestry development areas, whose distribution pattern is opposite to the risk distribution pattern of geomorphic disasters such as landslides, debris flows and soil erosion.

\section{Introduction}

Geomorphic disasters are geomorphic processes and phenomena that cause catastrophic impact and loss of human life, property and ecological environment due to the destruction of geomorphic stability caused by natural forces or human activities. Their types include collapse, landslide, debris flow and soil erosion. China is one of the countries most affected by natural disasters in the world. According to statistics, about $7.4 \times 107$ person-times are affected to various extent by landform disasters such as torrents, landslides and debris flows every year, and the direct economic loss is several billion yuan. At the same time, geomorphic disasters also profoundly affect global and regional ecological security issues such as forest vegetation degradation, land desertification and biodiversity reduction. Ecological security is a sign of the health and integrity of the ecosystem. As the relationship between the ecological environment and social development is getting increasingly complex, ecological security has been raised to the national strategic level by governments of various countries in order to maintain sustainable development of regional ecology. The principles and methods of landscape ecology can take advantage of the characteristics of that landscape structure components can easily store information. Landscape patterns and changes can directly reflect the changes in the structure and function of ecosystems, and are the result of the accumulation of various ecological processes. Therefore, many scholars have discussed and studied regional ecological security on the landscape scale. These studies provide basic ideas and examples for ecological security on the landscape scale, and also note the important impact of human activities on ecological security. However, most of the evaluation indicators are obtained by data interpolation on the administrative division scale, and the accuracy of the interpolation results is deeply affected by the interpolation method, sample point selection and sample size. At the same time, the research on the spatial-temporal dynamics of potential landscape ecological security caused by mountainous landform disaster factors (such as landslides, debris flows and soil erosion) is obviously insufficient. Therefore, it requires urgently in-depth research on the issues of, on the landscape scale, how to use grid GIS technology in the unit of river basin to spatially project many indicators of ecological security evaluation on the evaluation unit, and the characteristics of spatial-temporal changes of landscape ecological security under the stress of geomorphic disasters. 
The middle and lower reaches of the Yangtze River is a complex ecosystem integrating wetlands, forests, and grasslands, providing strong support for social and economic development. With the increasing intensity of human interference in the river basin in recent years, the water quality of the river basin has been seriously polluted, and the service functions of the river basin have been severely damaged. Starting from the narrow connotation of ecological security, based on the PSR model and ESI comprehensive evaluation model, with the help of RS / GIS, the preliminary assessment of the ecological security of the middle and lower reaches of the Yangtze River is provided, which provides a reliable basis for the governance and restoration of the ecological environment of the river basin.

\section{Research Area And Data Sources \\ 2.1 Study area}

The middle and lower reaches of the Yangtze River are located at $28^{\circ} 59^{\prime} \mathrm{N}-29^{\circ} 33^{\prime} \mathrm{N}, 119^{\circ} 49^{\prime} \mathrm{E}-120^{\circ}$ $44^{\prime} \mathrm{E}$, which originated in the valley between Longcong dock tip and Yan dock tip, Dapanshan Mountain, Pan'an County (Fig. 1 ). The main stream is about $475 \mathrm{~km}$ long and the watershed area is $18437.7 \mathrm{~km}^{2}$. The basin is dominated by hilly terrain, accounting for more than $60 \%$ of the total area. The area has a subtropical monsoon climate with four distinct seasons. The average annual temperature is $17.2^{\circ} \mathrm{C}$, and the average annual rainfall is $1419.9 \mathrm{~mm}$. The vegetation is dominated by subtropical evergreen broadleaved forest. The terrain is complex, with various landforms such as mountains, river valleys, loess, etc. Alpine peaks and canyons are distributed alternately, and the rivers are everywhere. It is famous for the huge mountain and deep ditch. The middle and lower reaches of the Yangtze River belong to the climate interlaced zone where the warm temperate zone transitions to the north subtropical zone. The vertical climate zones are clearly differentiated. The annual average temperature is $6-14.9{ }^{\circ} \mathrm{C}$, and the annual average precipitation is $400-850 \mathrm{~mm}$, and there is a decreasing trend from southeast to northwest.

\subsection{Data sources}

Data sources mainly include Landsat TM / ETM + satellite remote sensing images, landslide point data, multi-year average temperature and precipitation, DEM (30 m), topographic map (1: 50000$)$, MODIS NDVI data $(250 \mathrm{~m})$ and socioeconomic statistics yearbook data and general information on land use planning, environmental protection planning, etc. Among them, the land use information is mainly obtained by interpreting the image data of the 1990, 2002, and 2010 phases using supervision classification methods. And combining the land use classification standards of China and the actual situation of land resource utilization in the middle and lower reaches of the Yangtze River, the types of utilization of land in the study area are divided into 6 categories: cultivated land, forest land, grassland, water area, construction land, and unused land. At the same time, using topographic maps and Google Earth highresolution images (2010), field selection and verification were made on land use interpretation results and vegetation coverage, and interviews with local people were conducted. The accuracy of interpretation of each land use and cover was above $84 \%$ accroding to statistically calculation. The research data included digital image data, environmental monitoring data and socio-economic data, in which digital 
image data was provided by the Zhejiang Provincial Department of Environmental Protection, environmental monitoring data and socio-economic data were provided by relevant functional organs, and the questionnaire for the middle and lower reaches of the Yangtze River basin was obtained by the research team by field surveys of various towns in the study area, see Table 1 for details.

Table 1

Data sources

\begin{tabular}{|c|c|c|}
\hline Type of data & Detailed data & Source \\
\hline $\begin{array}{l}\text { Digital image } \\
\text { data }\end{array}$ & $\begin{array}{l}\text { Landsat satellite ETM }+ \text { image data (imaging time July } 19 \text {, } \\
2013 \text {, spatial resolution } 30 \mathrm{~m} \times 30 \mathrm{~m} \text { ) SPOT-5 satellite image } \\
\text { data (spatial resolution } 10 \mathrm{~m} \times 10 \mathrm{~m}) \text {; digital elevation } \\
\text { model DEM data }(\text { spatial resolution } 30 \mathrm{~m} \times 30 \mathrm{~m}) \text {, Digital } \\
\text { Land Use Database }(2000,2010)\end{array}$ & $\begin{array}{l}\text { Zhejiang Provincial } \\
\text { Department of } \\
\text { Environmental } \\
\text { Protection }\end{array}$ \\
\hline $\begin{array}{l}\text { Environmental } \\
\text { monitoring } \\
\text { data }\end{array}$ & $\begin{array}{l}\text { Water quality cross-section monitoring data, precipitation } \\
\text { data, river runoff data, point source and area source } \\
\text { pollutant discharge data }\end{array}$ & $\begin{array}{l}\text { Environmental } \\
\text { Protection Bureau, } \\
\text { Meteorological } \\
\text { Bureau, Water } \\
\text { Affairs Bureau, } \\
\text { Agriculture Bureau }\end{array}$ \\
\hline $\begin{array}{l}\text { Socio- } \\
\text { economic } \\
\text { data }\end{array}$ & $\begin{array}{l}\text { Questionnaire for Dongyang City and the Middle and Lower } \\
\text { Reaches of the Yangtze River in } 2012\end{array}$ & $\begin{array}{l}\text { Statistics Bureau, } \\
\text { field research }\end{array}$ \\
\hline
\end{tabular}

\section{Index System Construction Based On Psr Model}

\subsection{PSR model framework}

The farmland ecosystem is a semi-natural artificial ecosystem formed by humans intervening in natural ecosystems to meet the needs of survival, relying on land resources, and using crop growth and reproduction to obtain material products. The ecological security of cultivated land resources means that within a certain time and space scale, the farmland ecosystem is in a state of maintaining its normal functional structure and meeting the needs of social and economic sustainable development; in this state, there are stable, balanced, and abundant natural resources are available for use for the farmland ecosystem, and the ecological environment is healthy. It can be seen from this, the ecological security of cultivated land mainly includes two meanings. One is that the farmland ecosystem has a reasonable structure and functions normally in the process of human use of cultivated land resources. The second is that humans can continue to obtain cultivated land resources to meet the needs of health and survival

The PSR conceptual model was proposed by the OECD and UNEP of the United Nations. The model is based on causality, that is, human activities exert a certain pressure on the environment; the environment changes its original nature or the number (state) of natural resources; human society adopts certain measures to respond to these changes in order to restore environmental quality or prevent environmental degradation; it highlights the causal relationship between environmental stress and environmental 
degradation. The three links of stress, state, and response restrict and influence each other. It is the whole process of decision-making and formulation of countermeasures. Therefore, this paper draws on the PSR conceptual model as the basic framework of the cultivated land ecological safety evaluation index system (Fig. 2): population growth and economic and social development bring great pressure to the farmland ecosystem $(P)$; humans continue to develop land resources, through social economy activitis discharge pollution to the farmland ecosystem, changing the structure and function of the farmland ecosystem (S); under pressure, the farmland ecosystem reacts on the basis of the original state, and at the same time feeds back to the development process of the social economy; The humans make further respond to the farmland ecosystem's feedback further $(R)$, making policy adjustments, environmental protection, etc., to improve the state of farmland ecosystems, to maintain good structure and function, and to achieve sustainable development.

\subsection{Index system construction}

The PSR model is a framework model composed of environmental pressure, environmental state and social response indicators. Environmental stress refers to describing the burden (pressure) that human or natural factors directly or indirectly bring to the environment; environmental status reflects the current status of environmental quality, natural resources and ecosystems, and the state of changes in resources and environment over time; social response describes the degree of the responds and concern of the human society to the enviromental chang, as well as the relevant countermeasures and measures taken. At the landscape scale, the PSR model comprehensively considers the interaction relationship between risk pressure-environmental change-people (or society) response, and has strong flexibility and practicality. According to the principles of systemicness, practicability and possibility of data acquisition of the model index system, combined with the actual characteristics of the study area, the landscape ecological safety assessment index system of the middle and lower reaches of the Yangtze River Basin were refined and the weights of each index were determined, and grids were used for sampling.

$$
L_{\mathrm{LES} i}=\left(1-L_{\mathrm{LSP} i}\right) \times \varepsilon_{1}+L_{\mathrm{LSSi}} \times \varepsilon_{2}+L_{\mathrm{LSR} i} \times \varepsilon_{3}
$$

In the formula, --is the landscape ecological security index, -is the landscape ecological pressure index, -- is the landscape status index, and -- is the landscape ecological security index, -- is the weight. Number of the evaluation unit (grid). The larger the value, the higher the regional landscape ecological security. All indicators are normalized using formula (2):

$$
X^{\prime}=\frac{X-X_{\min }}{X_{\max }-X_{\min }}
$$

where, is a dimensionless index, is the original index, and represent the maximum and minimum values of the index, respectively. 
1) Landscape pressure index. In addition to the pressure brought by human activities and production, landscape ecological pressure is the largest risk source (pressure source) that affects the ecological security of the watershed. Therefore, this paper focuses on the The pressure on the landscape caused by landslide, debris flow and soil erosion. According to the probability and intensity of pressure sources in the basin, and previous research results, based on the ArcGIS technology platform, the risk distribution map of landslides, debris flow hazards and water and soil basin in the study area was obtained. At the same time, the analytic hierarchy process (AHP) was used to calculate the weight of the disaster factors of various appearances, and then the regional landscape ecological pressure index was constructed.

$$
L_{\mathrm{LSPi}}=P_{1 i} \times \omega_{1}+P_{2 i} \times \omega_{2}+P_{3 i} \times \omega_{3}
$$

In the formula, represents the landscape ecological pressure index of evaluation unit $i_{m}$, respectively represents the damage degree of landslide, debris flow and soil erosion, and ${ }_{\text {, }}$ respectively represent the weight of the hazards of landslide, debris flow and soil erosion. The larger the value, the greater the pressure of evaluation unit $i$ in the landscape ecological environment and the lower the regional ecological security.

2) Landscape state index. Landscape state indicators mainly consider the structural status and functional safety of landscape ecology, and are measured by landscape structure loss index and ecosystem service value, respectively. Among them, the landscape structure loss index is represented by the landscape fragmentation degree, landscape separation degree, and landscape fractal dimension weighting function; the larger the value, the more fragmented the landscape, the more unstable the structure, and the lower the landscape security. The ecosystem service value was calculated by the Costanza ecosystem service value model and the revised method proposed by Xie Gaodi [22]. The greater the value of ecosystem services, the safer the landscape function.

$$
\begin{aligned}
& L_{\mathrm{LSS}}=\left(1-S_{i}\right) \times \omega_{s}+E_{\mathrm{ESV}} \times \omega_{\mathrm{es}} \\
& S_{i}=a C_{i}+b N_{i}+c F_{i} \\
& E_{\mathrm{ESV}}=\sum\left(A_{\mathrm{Ak}} \times V_{\mathrm{VCl}}\right)
\end{aligned}
$$

In the formula, is the landscape state index, is the landscape structure index, EESV is the service value of the ecosystem in the study area, and is the weight of the two; is the landscape fragmentation index, is the landscape separation index, and is the landscape fractal dimension; $a . b$ and $c$ are the weight of each landscape pattern indicator. According to relevant research, combined with the field characteristics of the study area, weights of the landscape fragmentation index, separation degree and landscape fractal dimension vulnerability were assigned $0.5,0.3$ and 0.2 , respectively. AAk is the area of the land use type 
in the study area $\left(\mathrm{hm}^{2}\right)$, and VVCk is the ecological service value per unit area of the kth land use type [yuan $\left.\left(/ \mathrm{hm}^{2} \cdot \mathrm{a}\right)\right]$.

3) Landscape response index. Based on the previous research results and the principle of quantification of indicator space, combined with the characteristics of ecological function zoning in the study area, the degree of regulation and control of different ecological function areas in different periods reflects the degree of response of people and society to environmental changes. The greater the degree of response, the higher the degree of landscape ecological security. Using the Delphi method, the response indexes of different functional areas in the basin were assigned, as shown in Table 2.

Table 2

Assignment of the response index of the functional area

\begin{tabular}{|lllllll|}
\hline $\begin{array}{l}\text { Year } \\
\text { (year) }\end{array}$ & $\begin{array}{l}\text { Forestry } \\
\text { Development } \\
\text { Zone }\end{array}$ & $\begin{array}{l}\text { Pastoral } \\
\text { Development } \\
\text { Zone }\end{array}$ & $\begin{array}{l}\text { Farming } \\
\text { area }\end{array}$ & $\begin{array}{l}\text { Nature } \\
\text { reserve } \\
\text { area }\end{array}$ & $\begin{array}{l}\text { Ecological } \\
\text { security control } \\
\text { area }\end{array}$ & $\begin{array}{l}\text { Water } \\
\text { area }\end{array}$ \\
\hline 1990 & 0.8 & 0.6 & 0.8 & 0.5 & 0.4 & 0.2 \\
\hline 2002 & 0.9 & 0.7 & 0.9 & 0.7 & 0.6 & 0.2 \\
\hline 2010 & 1.0 & 0.8 & 0.9 & 0.9 & 0.8 & 0.2 \\
\hline
\end{tabular}

\section{Empirical Researches}

According to the above weights combined with standardized data, a comprehensive evaluation method was used to evaluate the forest ecological security of 85 counties and districts in Hubei Province from 1999 to 2014, and the forest ecological security index was calculated. According to the value of forest ecological security index level and the characteristics of ecosystem evolution, referring to the research results of Jiang Weiguo and Nan Ying, through the GIS technical analysis module, and referring to the evaluation level, the evaluation results of the forest ecological security index were divided into five levels: excellent $(0.8 \sim 1.0)$ and good $(0.6 \sim 0.8)$, general $(0.4 \sim 0.6)$, relatively poor $(0.2 \sim 0.4)$ and poor $(0 \sim 0.2)$, and a spatial distribution map was made (Fig. 3).

From the overall situation of forest ecological security, in 2014, the number of excellent counties accounted for $14.12 \%$, the number of good counties accounted for $78.82 \%$, and the number of general counties accounted for $7.06 \%$. The overall status of Hubei Province is in a good condition, which can exert the service function of the forest ecosystems relatively well. The forest ecosystem is in a sustainable state. From 1999 to 2014, the changes in the forest ecological security level of the county in Hubei Province are shown in Fig. 3. From 1999 to 2014, the forest ecological security situation in Hubei Province has improved to a certain extent. Most county ecological security conditions are at the "general" level, and there is no "excellent" level. In 1999, there was a "poor" county for forest ecological security, and 
from 2004 to 2014, the county changed from "poor" to "relatively poor" and eventually developed into "general." From 1999 to 2009, the number of "relatively poor" counties gradually decreased until 2014, when the number was zero. From 1999 to 2004, the level of forest ecological security in some counties fell from "good" to "general". From 2009 to 2014, the ecological status of such areas improved.

Hubei's "Two Circles and One Belt" refers to: Wuhan City Circle, Western Hubei Eco-Cultural Tourism Circle and Yangtze River Economic Belt. Due to the locational conditions, natural geographic conditions and the differences in forest resources among counties, the distribution of forest ecological conditions among counties are uneven. Wuhan City Circle refers to Wuhan, the largest city in the central region, covering 8 large and medium-sized cities around Huangshi, Ezhou, Huanggang, Xiaogan, Xianning, Xiantao,

Tianmen, and Qianjiang. Huangshi is the deputy central city of the city circle. The Western Hubei EcoCultural Tourism Circle includes 8 cities (forest areas) including Xiangyang, Jingzhou, Yichang, Shiyan, Jingmen, Suizhou, Enshi, and Shennongjia located in the west of Hubei, and is an important ecological function zone in the country.

In the Wuhan City Circle, the forest ecological safety index of all counties is above 0.4 , indicating that the forest ecosystems in these counties are still stable and can play a basic forest ecological function. Good counties account for $83.78 \%$, and Yunmeng County in Xiaogan iand Huangzhou District in Huanggang, as well as the Huangshigang District, Shihuiyao District, Tieshan District and Xialu District in the subcentral cities of the Wuhan City Circle, are in a general state. Overall, the forest ecological safety status of the Wuhan City Circle is relatively good. At the same time, the forest ecological security status of Wuhan is good, and only the Daye County and Yangxin County of Huangshi City are good. Therefore, the forest ecological security status of Wuhan City, the central city circle of Hubei Province, is better than that of Huangshi, the sub-central city of the city circle.

In theWestern Hubei Eco-Cultural Tourism Circle, the forest ecological safety index of all counties is above 0.6 , indicating that the forest ecological safety status of these counties is better, and the excellent counties account for 1/4. Especially, the forest ecology of the Shennongjia forest area has the highest safety index in Hubei Province, and its forest coverage rate has reached more than $90 \%$. Compared with the Wuhan City Circle, the forest ecological security in the Western Hubei Eco-Cultural Tourism Circle is better. This conclusion coincides with the Hubei Province 's strategic layout of the "Two Circles and One Belt", which shows that the evaluation results of this indicator system are relatively realistic.

Figure 4 shows the spatial distribution and temporal variation characteristics of the evaluation results of forest ecological security in Hubei Province from 1999 to 2014. It can be seen from Fig. 4 that from the perspective of spatial distribution, the distribution of forest ecological security index in Hubei Province is uneven, and the forest ecological security status in western Hubei is better, among which Shennongjia forest area is the best. The forest ecological security status of Shiyan City, Enshi City and Yichang City is relatively good, followed by the eastern part of Hubei Province, Huanggang, Huangshi and Xianning areas, and that of the central part is lower. In 2008, Hubei Province began to construct the "Western Hubei Ecological Cultural Tourism Circle", areas in which have become the focus of protection, in cluding the 
world cultural heritage, world intangible cultural heritage, national nature reserves, national intangible cultural heritage, national scenic spots and national geoparks. The large investment in the development of the tourism circle not only has protecte the water source of the Three Gorges Project and the South-toNorth Water Diversion Project, but also has produced huge ecological value and tourism benefits. It has truly achieved good and rapid development. Therefore, Hubei Province's Ecological practice has verified that the improvement of forest ecological security status can lead to a win-win situation of ecological, social and economic benefits.

From the perspective of time trends, the forest ecological security index of Hubei Province was 0.49 in 1999 and rose by $4.08 \%$ in 2014 . This result shows that: first, the overall forest ecological security status of Hubei Province is relatively good, and it shows a favorable change trend. Second, the forest ecological security index of Hubei Province has not increased much in the past 16 years. From the perspective of county distribution, $78.82 \%$ of the counties showed an upward trend, indicating that the quality of forest ecological safety in most counties has been improved. The counties with the most obvious increase was Huanggang District of Wuhan City Circle (56.73\%), Yunmeng County of Xiaogan (47.48\%) and Shiyan Danjiangkou City (26.58\%) in the Western Hubei Ecological Cultural Tourism Circle. The majority $(74.12 \%)$ of the counties' growth rate remained within $20 \% .12 .94 \%$ of the counties' forest ecological safety index showed a downward trend. Among them, Huangshigang District, Shihuiyao District, Tieshan District and

the Xialu District of Huangshi City, the sub-central city of the urban circle, had more obvious declines. The reason for the decline is that the wastewater and SO2 discharge in economic growth increased the pressure on forest ecosystems. The forest ecological security situation in 7 counties including Dongmen District of Jingmen and Dangyang City of Yichang remained basically unchanged. Overall, the forest ecological security system in Hubei Province is more stable and healthy, but the forest ecological security index of a few counties shows a downward trend.

\section{Conclusions}

From the evaluation of the coordination degree of the cultivated land ecological safety subsystem, it can be seen that many areas in the basin show a negative correlation between the comprehensive evaluation score and the coordination degree evaluation value, indicating that the potential ecological crisis exist in the region is widely. Based on the aforementioned empirical research, the following conclusions can be drawn in this article:

(1) The economic development mode has a relevant influence on the ecological security of cultivated land. In the less-developed areas of central China, industrialization started late. And under the current macro scope background of "capacity reduction", transforming economic development methods, promoting the development of clean industries, and accelerating the construction of ecological civilization can take a good care of both economic development and the ecological health of cultivated land in the same time. "It requires not onlygold and silver mountainsbut also green water and green mountains". Only by realizing the organic symbiosis of the natural-social system can sustainable development be achieved. Therefore, integrating the green economic development mode and the 
ecological environment health is an effective way to ensure the ecological security of cultivated land. (2) The topography, landform, and water and heat conditions have an inherent impact on the ecological security of cultivated land. In most areas of the middle and lower reaches of the Yangtze River, mountainous and hilly landforms and uneven distribution of water and heat have resulted in the fragmentation of cultivated land and traffic congestion, so that large-scale management of cultivated land cannot be achieved, which has many negative impacts on the ecological security of the cultivated land and the agricultural economy. Therefore, exploring a reasonable scale economic operation mode according to the actual situation to adapt to such topography, landforms and water and heat conditions is the way out for the ecological mitigation of cultivated land in this area, and it is the only way to realize the sustainable utilization of cultivated land resources. (3) Pollution treatment is a necessary part for ecological mitigation and treatment of cultivated land. There are many sources of ecological pollution in cultivated land. How to effectively manage industrial "three wastes", agricultural area source pollution, and the pollution to the cultivated land by household pollution are inevitable problems in maintaining the health of the cultivated land system. And the root problem lies in the ambiguous right of cultivated land property rights, i.e., the "tragedy of the commons". Therefore, it is necessary to curb this kind of rentseeking of pollutant emission and from the root by clarifying the property rights of the cultivated land, and at the same time, the pollutant discharge behavior should be severely punished, and the fundamental suppress should be ensured through legislation and other measures. Thus, sustainable use of cultivated land resources can be achieved.

\section{Declarations}

Funding $\llbracket$ Not applicable

Conflicts of interest/Competing interests $₫$ Not applicable.

Availability of data and material :The data sets supporting the results of this article are included within the article.

Code availability:Not applicable.

Authors' contributions: contributed to the conception of the study;

Wang Dechun contributed to the whole article include the conception of the study,the experiment, analysis and manuscript preparation, the data analyses and wrote the manuscript, the analysis with constructive discussions.

Additional declarations for articles in life science journals that report the results of studies involving humans and/or animals:Not applicable.

Ethics approval:Not applicable.

Consent to participate :Not applicable. 
Consent for publication:Not applicable.

\section{References}

1. Liling Z, Hongzhao C, Economics SO, et al (2014) An Empirical Analysis of the Relationship between Industrial Structure Adjustment and Environmental Pollution--Based on Fujian Province[J]. journal of fuqing branch of fujian normal university

2. HAN Nan. A SPATIAL ECONOMETRIC ANALYSIS OF ECONOMIC GROWTH,INDUSTRIAL STRUCTURE AND ENVIRONMENTAL POLLUTION IN CHINA[J]. Environmental Engineering, 2016

3. Dou W, Fukuoka K, Kohno H (1998) An Analysis About the Correlation between the Industrial Structure and Environmental Pollution[J]. Studies in Regional Science 29(3):185-204

4. Jianxin Xiong B, Peng D, Chen. Empirical analysis on the eco-environmental effect based on the change of industrial structure - A case study of West Dongting Lake region[C]// International Conference on Remote Sensing. IEEE, 2011

5. Yang HX (2013) An Analysis of the Development of Tourism in the Mountainous Area and the Ecological Environment Protection - Take Jinsixia Park as an Example[J]. Applied Mechanics \& Materials, 295-298:2233-2237

6. Wu T, Peng YC, Lv K (2013) Research of Relationship between Shanghai Industrial Structure and Environmental Pollution[J]. International Journal of Advances in Management Science 2(4):127-132

7. Li MA, Fengjun J, Yi L (2012) Spatial Pattern and Industrial Sector Structure Analysis on the Coupling and Coordinating Degree of Regional Economic Development and Environmental Pollution in China[J]. acta geographica sinica 14(3):327-337

8. Zhang Y, Yang Z, Li W (2006) Analyses of urban ecosystem based on information entropy[J]. Ecol Model 197(1-2):1-12

9. Є.А. Бакулін. Determination of industrial buildings safety level under influence of aggressive industrial environment[J]. Proceedings of National Aviation University, 2005, 23(1):54-59

10. Ruipeng W. The Dynamic Relationship Between Industrial Structure,Urbanization and Environmental Pollution--A Empirical Study Based on VAR Model[J]. journal of industrial technological economics, 2013

\section{Figures}




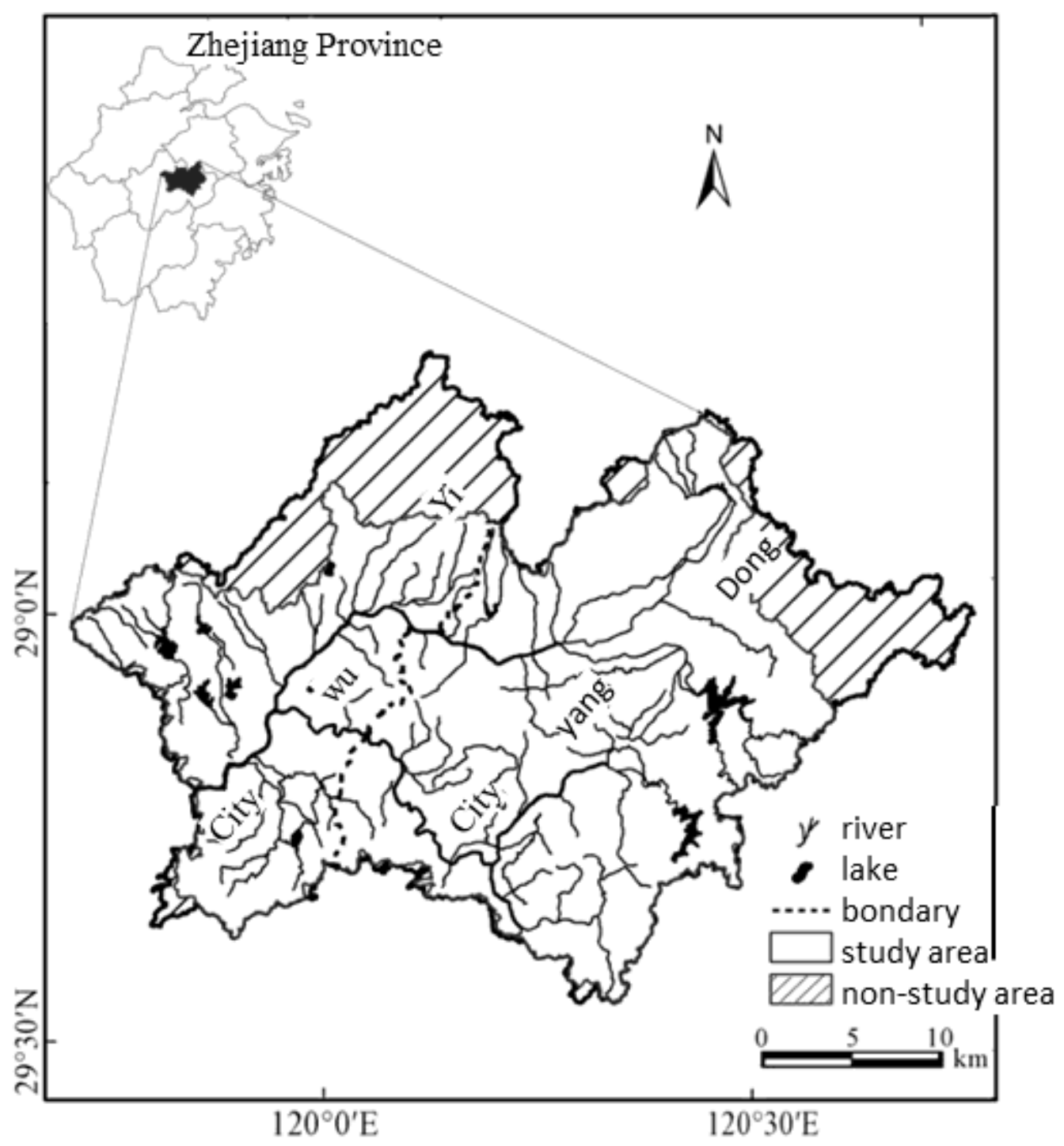

Figure 1

Study area 


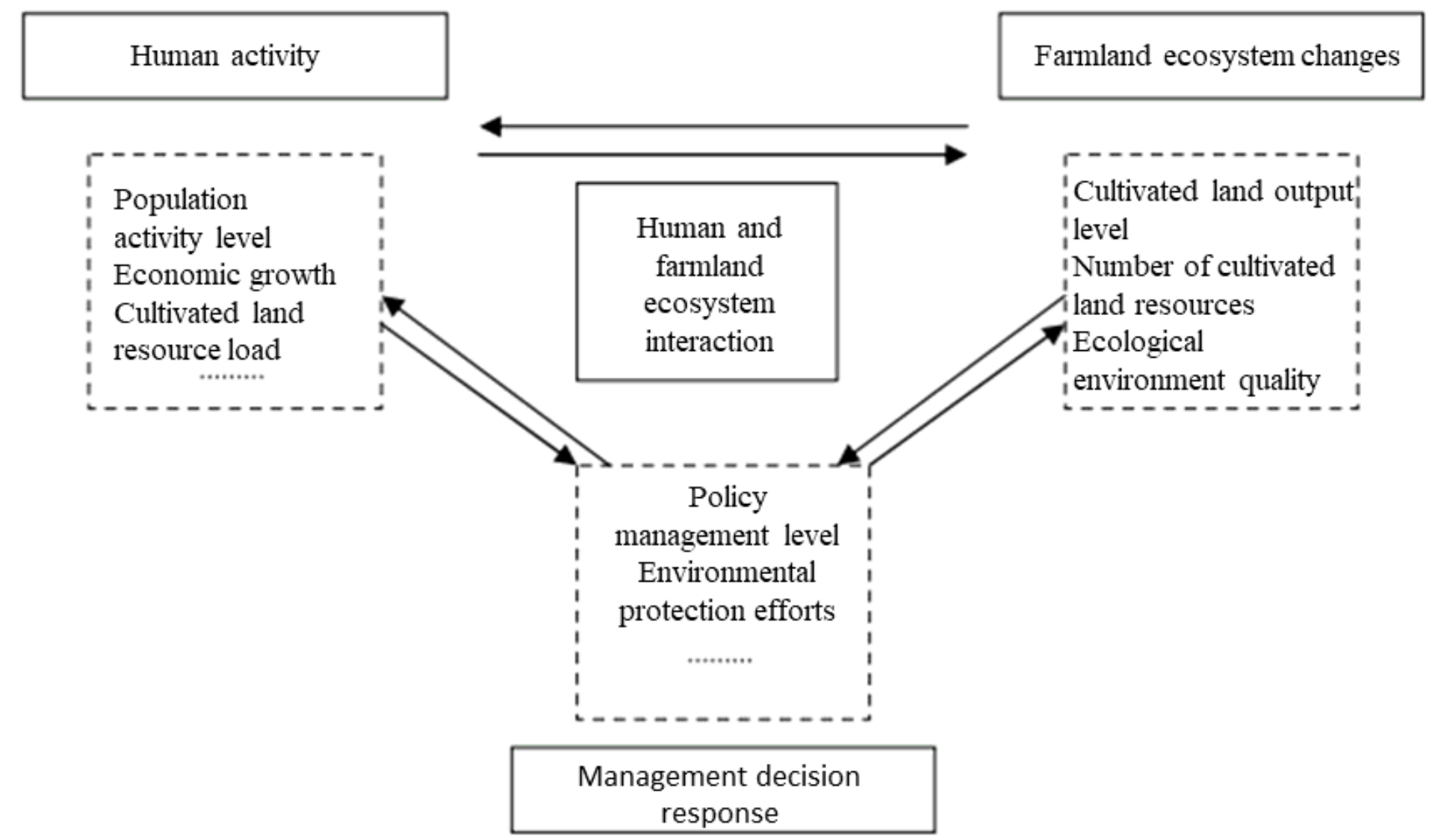

Figure 2

PSR model framework for ecological security evaluation 


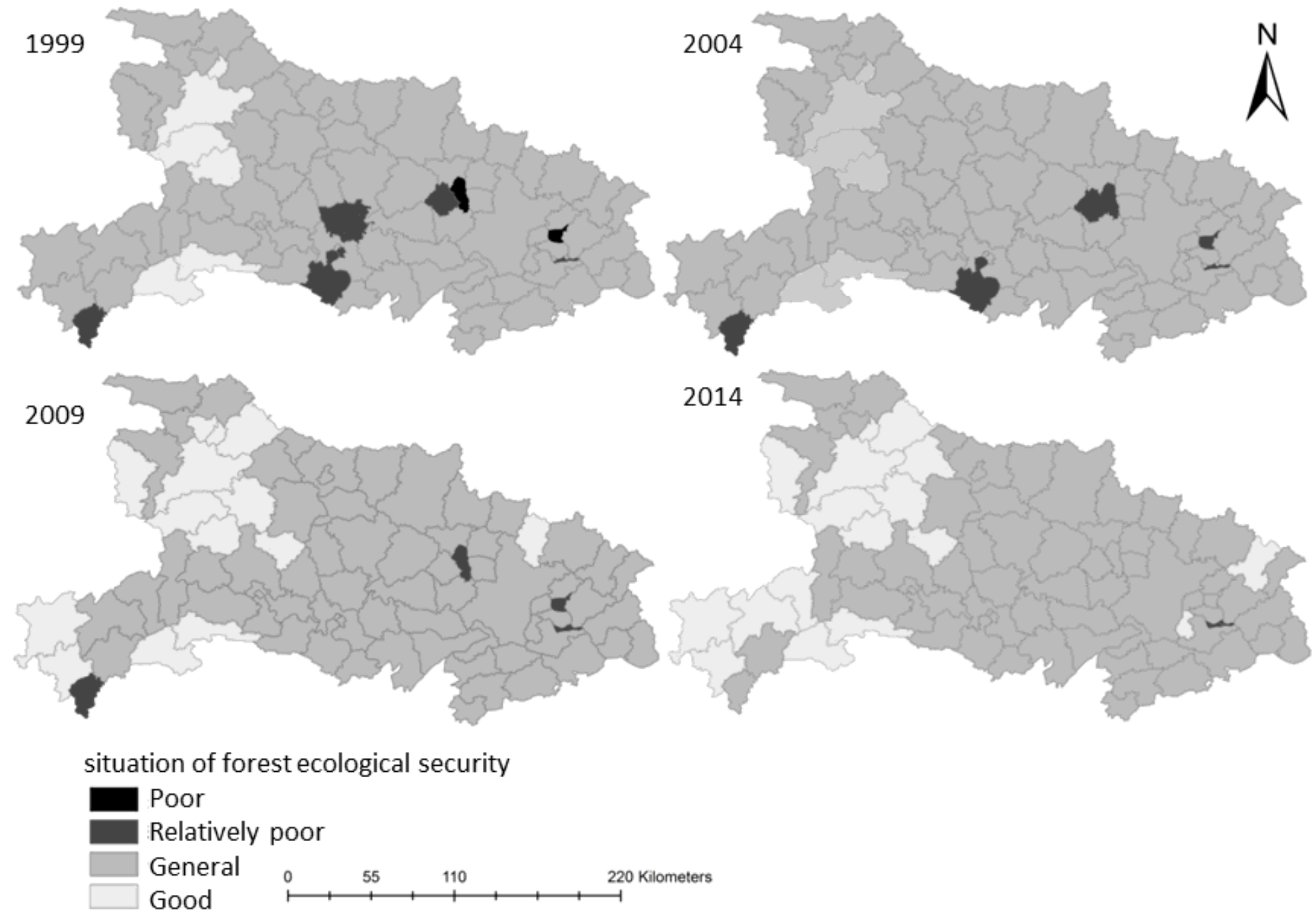

Figure 3

Distribution map of county forest ecological security grades in Hubei Province 


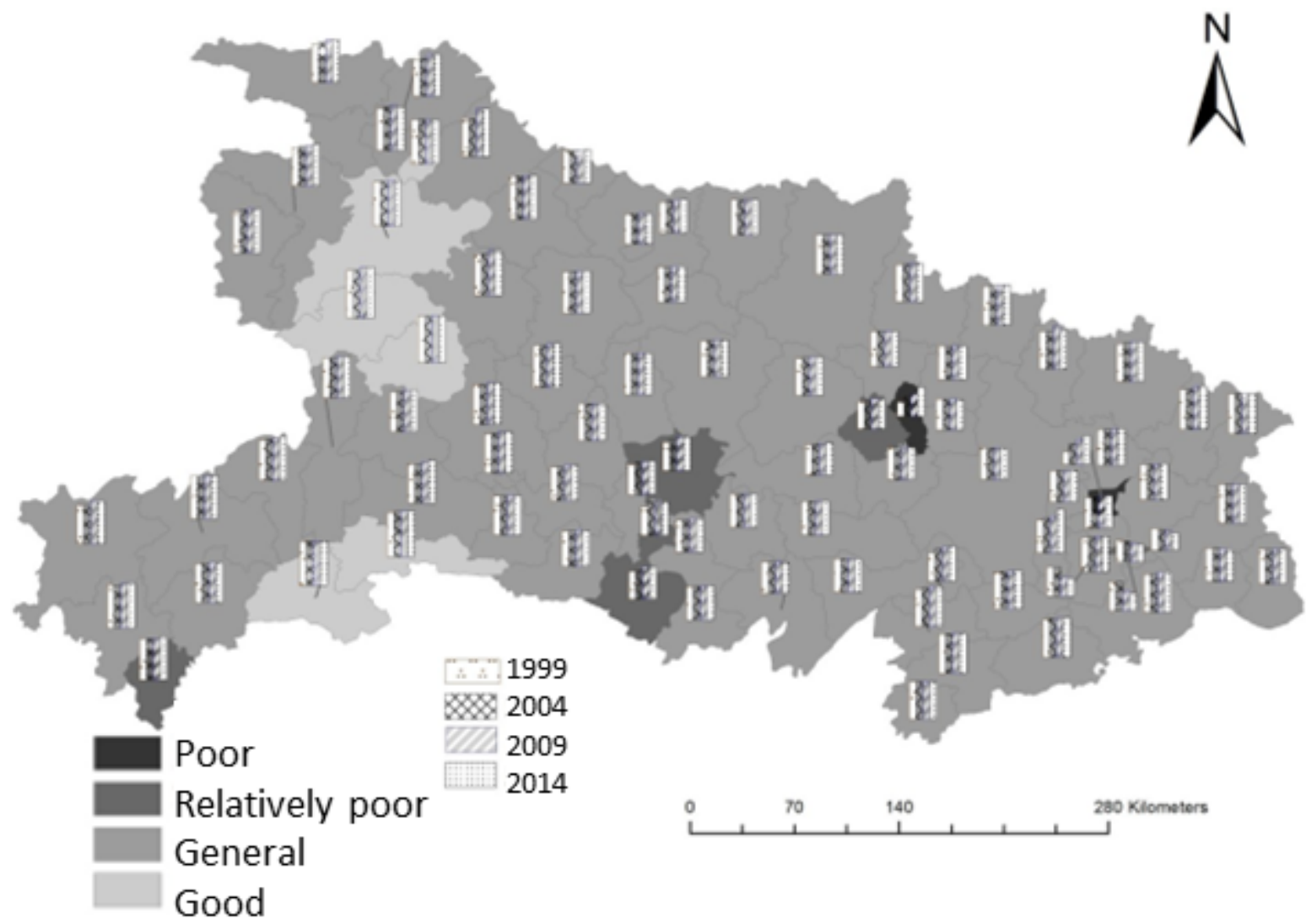

Figure 4

Distribution of forest ecological safety assessment results 